\title{
A Short Review on Polymer Nanocomposites for Enameled Wires: Possibilities and Perspectives
}

\author{
M. G. Danikas \\ Democritus University of Thrace, Department of Electrical \\ and Computer Engineering, Power Systems Laboratory, \\ Xanthi, Greece \\ mdanikas@ee.duth.gr
}

\author{
S. Morsalin \\ University of New South Wales, Scholl of Electrical \\ Engineering and Telecommunications, High Voltage \\ Laboratory, Sydney, Australia \\ Sayidul.morsalin@unsw.edu.au
}

\begin{abstract}
Polymer nanocomposites constitute a new generation of insulating materials, capable of offering better electrical, thermal and mechanical properties. Past research indicated that such materials may replace conventional polymers for a variety of industrial high voltage applications. In the present paper, polymer nanocomposites are investigated regarding the insulation of enameled wires. Possible nanocomposite candidates are discussed.
\end{abstract}

Keywords-enameled wires; nanocomposites; nanoparticles; partial discharges; charges; voltage rise time; insulation deterioration

\section{INTRODUCTION}

The present paper aims to provide a short review on polymer nanocomposites for enameled wires. It is the aim of this paper to shed some light on the polymer nanocomposites and their possible applications in enameled wiring. In the light of the advent of power electronics and the ever more frequent use and interaction with high voltage apparatus, it is highly interesting to investigate such possibilities of applications of the new materials. The advent of power electronics arrangements into electrical networks provide additional efficiency to power converters [1,2] however it also seems to be the cause of some distortions in current as well as in voltage. Such distortions may in turn cause a reduction in the reliability of the insulation systems and premature aging. In fact, the largest discharges, one of the most deleterious causes of insulation degradation, tend to occur closest to the front of the applied voltage pulse [1].

Polymer nanocomposites have been the subject of intensive research for the past 25 years $[3,4]$. A wealth of experimental results as well as a number of proposed models has been published regarding polymer nanocomposites. Nanocomposites, mainly because of the dispersed nanoparticles in a base polymer, seem to present interesting properties and provide improved electrical, thermal and mechanical properties compared to their conventional counterparts. Polymer nanocomposites are being tried on both ac and dc applications [5]. No effort was taken to investigate possible lifetime relationships in the context of this paper since this is beyond the scope of the present work. It goes without say that the present review does not cover the whole issue of power electronics arrangements in conjunction with the whole range of insulating materials and systems. It is just an attempt to approach the subject of enameled wires in relation with the recently developed polymer nanocomposites.

\section{ENAMELED WIRES}

Enameled wires are used for applications requiring tight coils, such as inductors and electrical motors. Their insulation consists of films from polymeric materials, such as polyurethane, polyurethane resin, polyamide, polyester, polyimide and also several combinations of them $[6,7]$. Enameled wires have thin insulation. Such insulation must be flexible, extensible, and tough. It must withstand mechanical vibrations, have good dielectric strength, be stable and have a long lifetime. In [8], detailed information is given on the variety of insulating materials for enameled wires regarding their thermal classes and their possible applications. Such insulation may suffer from electrical, mechanical and thermal stresses. Research referring to the ageing of such insulation systems indicates that thermal stresses are an important ageing factor [9]. In [9], it was pointed out that there are two basic ageing mechanisms determined by the critical temperature $\theta_{\mathrm{c}}$. Below the critical temperature, a thermal ageing occurs whereas above the critical temperature a sudden thermal breakdown may occur. Earlier studies indicated that with polyester-type magnet wires (and in general with film-coated magnet wires and impregnating varnishes) extrapolation of data is allowed only after realistic and appropriate requirements have been met in regard to linearity and other factors such as maximum and minimum average life data [10]. Relevant effects, such as those of increasing temperatures because of repeated electric motor starts, and their influence on the lifetime of wires, were analyzed in [11].

Serious reservations were expressed earlier about the possibility of data extrapolation, especially in the case in which two factors are accelerated simultaneously [12]. Aging factors - interacting with each other and combining - are difficult to quantitatively analyze and study [12-14]. Heat shock resistance, flexibility and windability are among the factors which matter in order to choose the appropriate material for enameled wires. Polyurethane based with polyamide outer coating, among others, was developed for this purpose. 
Moisture resistance is another important factor for choosing the right material. It is usually difficult to make a choice since chemical options in some cases favor thermal life and functionality whereas at the same time they render the enameled wire less flexible and less heat shock resistant [15]. Also properties, such as embrittlement, are affected by the formulation of the base polyester resin and by the choice of monomer [16].

\section{POLYMER NANOCOMPOSITES AND RELATED MODELS}

Polymer nanocomposites have been the subject of intensive research in recent years [3-5]. It is interesting to note that the problem with the interfaces that is envisaged with conventional insulating materials is not the same in the context of polymer nanocomposites [17]. In polymer nanocomposites, interfaces seem to play a different role. Nanoparticles dispersed in a conventional polymer interact with the surrounding polymer matrix and the so-called interaction zone contributes to the improvement of the properties of the base polymer [18]. A considerable amount of publications has dealt with the question of interfaces in polymer nanocomposites. As was mentioned before, main interface models - referring to nanocomposites are the Lewis model, the Wilkes model, the Tanaka multi-core model, Tsagaropoulos' model, the potential barrier model, the interphase model, the polymer chain alignment model, the water shell model, the dual layer model, the physical model for the explanation of surface degradation mechanism, the physical model for tree growth, Chen's model and the percolation model $[19,20]$. All these models have been analyzed in detail in [20]. In a further attempt to explain electronic transport in polymer nanocomposites, a novel concept considering the nanoparticles as quantum dots (QDs) was proposed. In such a consideration, nanoparticles are thought to be QDs of nm size and are taken as carrier traps [21]. Simulation studies regarding partial discharges and electrical trees for both conventional polymers and polymer nanocomposites have been reported in [22]. Simulations have to certain extent considerable success, especially regarding qualitative (but not quantitative) comparisons. Generally speaking, polymer nanocomposites present higher breakdown strength and they are more resistant to electrical trees because the nanoparticles they contain seem to act as nano-barriers [23-27].

\section{ENAMELED WIRES AND POLYMER NANOCOMPOSITES}

Enameled wires are a critical component of several significant devices (radios, televisions, computers, large and small electrical motors, automobiles, refrigerators). Both World War I and World War II resulted in rapid growth and expansion in the enameled wire industry [28]. Breakdown strength and partial discharges have been some of the major concerns of the insulation in such wires $[6,7,29]$. The need of a more efficient control of the energy conversion equipment and the wider use of the pulse width modulated waveforms put additional stresses on the insulation systems. The aforementioned factors together with the advent of polymer nanocomposites create new challenges for potential applications [30-32]. High reliability of the insulation of enameled wires is required having in mind the use of electronic variable speed drives. The presence of fast rising or falling voltages can lead to overvoltages and consequently to the starting of partial discharge activity [33]. The results of [33] seem to favor some materials, either with or without nanoparticles. However, it seems that layered silicate is an appropriate additive to epoxy monocomponent resin and to solventedalkydic resin, giving rather encouraging inception voltages. The importance of the environment in which insulating systems function, is adequately emphasized in [34], where it was pointed out that standards used for land-based insulation systems are not likely to provide good guidance for ship insulation system design. Sinusoidal voltage waveforms cause different electrical stresses from pulse voltages, since the latter can be repetitive with a high level of voltage rise fronts (slew rates). Slew rates can attain values of tens of kilovolts per microsecond and voltage pulse repetition frequency of up to several tens of kilohertz. Electric motor insulation systems may be affected by such phenomena [35, 36]. Internal partial discharges consist a real threat since they are intimately related to resin-rich insulating systems [37].

Various mixtures were tried in order to improve the electrical performance of enameled wires. Thus in [38], different proportions of nanoparticles $(1 \mathrm{wt} \%, 3 \mathrm{wt} \%$ and 5 wt $\%)$ from different substances $\left(\mathrm{ZrO}_{2}, \mathrm{Al}_{2} \mathrm{O}_{3}, \mathrm{CNT}\right.$ and $\left.\mathrm{ZnO}\right)$ were tested. It was indicated that the optimum performance was given by the enamel filled with $3 \mathrm{wt} \% \mathrm{Al}_{2} \mathrm{O}_{3}$ nanoparticles regarding the inception and extinction voltages, whereas the enamel with $1 \mathrm{wt} \% \mathrm{ZrO}_{2}$ nanoparticles presented the highest breakdown strength. Electrical properties are not the only ones to take care of, as is pointed out in [39]. Aromatic polyamide imide resins (PAI)-silica hybrid films seem to have a better heat and abrasion resistance when compared with conventional PAI insulation. There seems to be a correlation between silica content and Young's modulus without, however, affecting the flexibility of the film. Such wires were also surge-resistant to partial discharges, rendering them suitable for hybrid and electric vehicles, as later research showed [40]. Relevant work on silica/polyamide-imide composite films for enameled wires revealed that the way the silica nanoparticles are treated plays a dominant role in determining the behavior of the nanocomposite. Spherical silica nanoparticles modified with the cationic surfactant cetyltrimethyl ammonium bromide (CTAB) were successfully dispersed into the PAI matrix and improved the thermal stability and decomposition temperature of the pure PAI polymer [41]. The partial discharge behavior was also improved since the authors of [41] considered that charged particles are reflected and scattered around the silica nanoparticles, improving thus the partial discharge resistance. Their interpretation as to why partial discharges seem to be less in nanocomposites than in conventional polymers conforms with the interpretations given in $[19,23]$.

The authors of [41] suggested that the optimum percentage of nanoparticles into the PAI matrix is $3 \mathrm{wt} \%$. However, in yet another study by the same authors, no agglomerations of silica nanoparticles were observed up to $10 \mathrm{wt} \%$ [42]. In another study, polyesterimide and polyester were investigated and compared with their nanocomposite counterparts having nanoparticles of $1 \mathrm{wt} \%$ of nanosilica, $1 \mathrm{wt} \%$ of zinc oxide and $3 \mathrm{wt} \%$ montmorillonite (MMT). The nanocomposites presented better resistance to partial discharges, better water absorption and better thermal endurance [43]. Polyimide film 
nanocomposites showed higher breakdown voltage and lower probability of breakdown when they have nanoparticles of $\mathrm{SiO}_{2}$ with $1 \mathrm{wt} \%$ rather than with $3 \mathrm{wt} \%$ inclusions (results analyzed with the Weibull distribution) [44].

Further studies on polyamide-imide (PAI) in combination with nanoparticles of alumina and silica revealed that alumina loadings of about 5-7.5 wt $\%$ offered an improvement in breakdown strength, better endurance testing results and moderate improvement in thermal performance compared with the unfilled material. Alumina seems to offer a more significant improvement than silica regarding breakdown strength and partial discharge behavior, because of the larger difference in permittivity between PAI and alumina. Such a difference causes a larger scattering of electrons and thus a reduction of mean free path. Experiments with twisted wires indicated that, as corona erodes the polymer during endurance testing, nanoparticles build up on the surface of the polymer. The nanoparticles have a higher resistance to damage from the discharges, and in this way they help to improve the endurance [45]. Nanocomposites consisted of enamel, epoxy and zirconia nanoparticles (in mixtures of $1 \mathrm{wt} \%, 3 \mathrm{wt} \%$ and $5 \mathrm{wt} \%$ ) were investigated in [46], where it was shown that the mixture with 5 $\mathrm{wt} \%$ presented the highest inception and extinction voltages together with the highest melting point. Silica nanoparticles were used in order to produce enameled wires from polyamideimide. The novelty in this case was the use of a lowhygroscopicity solvent consisted of MDI (diphenylmethane-4, 4'-diisocyanate) and of TMA (trimellitic anhydride), so that to obtain a nanocomposite which had a better voltage endurance and thermal endurance than the conventional polyamide-imide polymer [47]. The nanocomposite also excelled regarding other critical parameters, such as flexibility, resistance to abrasion and partial discharge inception voltage. However, the aforementioned paper presented the improvements of nanoparticle contents in terms of 'arbitrary units' instead of the more convenient percentages in $\mathrm{wt} \%$.

A comparison between round wires and rectangular wires was presented in [48], where the authors studied their performance with various temperatures $\left(250^{\circ} \mathrm{C}-2300^{\circ} \mathrm{C}\right)$. Although the round wires proved to be slightly better in electrical performance than the rectangular ones (regarding dielectric strength and partial discharge inception voltage), the authors proposed a mixed insulation for rectangular wires, which consisted of enamel layer and PAI insulation, with the latter having a reduced permittivity. Partial discharge studies is one of the most reliable processes in order to see what sort of material may be used for enameled wires, as discussed in [49]. Although no nanocomposites were used in the latter paper, a discrimination between various materials as well as between aged and non-aged materials can be done based on partial discharge measurements. Partial discharge inception voltage measurements with enameled wires with nanoparticles $\left(\mathrm{SiO}_{2}\right.$, $\mathrm{TiO}_{2}, \quad \mathrm{Al}_{2} \mathrm{O}_{3}$ ), however, did not discriminate between nanocomposite enameled wires and the conventional ones, although the former showed an improved total life and residual life [50]. In [50], a critical partial discharge was observed which was consistent with the breakdown point, something also noted many years ago with conventional polymers [51]. Nanofilled polyamide-imide twisted pair specimens were investigated in [52], where it was shown that they performed better regarding dielectric strength due to pulsed voltages as well as regarding partial discharge activity compared with conventional polyamide-imide specimens (the nanofilled specimens had nanoparticles of $\mathrm{SiO}_{2}$ in portion of $8 \mathrm{wt} \%$ ). As mentioned above, partial discharge measurements, especially in their more complete form (i.e. giving information w.r.t. the phase angle of the discharges, their pulse shape and their sequence), render an overall picture of the difference between nanocomposites and the conventional polymers. It was shown that a combination of micro and nano particles in a polymer may enhance the dielectric strength w.r.t. the conventional polymer. An addition of $5 \mathrm{wt} \%$ nanoparticles in epoxy resin may influence the permittivity of the resulting nanocomposite, since the change in permittivity may be due to the permittivity of the added nanoparticles and also to the immobilizing of the molecular chains in the interaction zone. Once again, partial discharge measurements and erosion studies proved to be indispensable in order to classify the various types of microand nanocomposites [53].

Polyesterimide resin filled with nanosilica, montmorillonite and aluminium oxide in portions of $1.5 \mathrm{wt} \%$ were investigated in [54]. Thermoanalytical methods, breakdown measurements and partial discharge measurements showed that hydrophilic nanosilica as well as aluminium oxide presented the best results w.r.t. thermal stability, dielectric strength and partial discharge resistance. The authors, however, did not explain why nanoparticles from the aforementioned substances presented better results than hydrophobic nanosilica and montmorillonite nanoparticles. The validity of partial discharge measurements when investigating the effect of repetitive square voltage frequency on enameled wires was discussed in [55], where it was noted that a higher voltage frequency would decrease the partial discharge events with lower magnitudes. Such events would not be induced in some weak insulation points because of the inadequate time to generate the initial electrons. Different square voltage frequencies may result in different surface charge decay ratios and different initial electron emission probabilities. Reference [55], however, did not mention any comparison between various insulating materials for enameled wires. Similar observations, regarding the higher voltage frequency and the partial discharge activity, were noted in [56]. In the same work, polyimide insulation was filled with nanoparticles of $\mathrm{TiO}_{2}$ (which help in achieving better thermal conductivity and improved electrical properties), nanoparticles of fumed silica $\left(\mathrm{SiO}_{2}\right)$ (which have extremely large surface area, good thermal properties and impart excellent electrical and mechanical characteristics to dielectric coatings) and nanoparticles of $\mathrm{Al}_{2} \mathrm{O}_{3}$ (which have excellent electrical and thermal properties). Such nanoparticles were added to the base polymer at about $1 \mathrm{wt} \%$. The improvement of dielectric strength was attributed in [56] to the impinging of charged particles on the nanoparticles, preventing thus further collisions with the organic material. In this way, the creeping distance is extended, and the collision energy of the charged particles is lowered considerably by the reflection and scattering so that the erosion is suppressed. This explanation is in perfect agreement with that reported some years earlier [57]. Concentrations larger than $1 \mathrm{wt} \%$ may result in diminishing the 
mechanical strength as well as the dielectric strength. Polyimide with fumed silica nanoparticles showed low surface roughness and higher dielectric strength as compared with polyimide with the other aforementioned types of nanoparticles.

An interesting piece of work was presented in [58], where the authors compared polyamide-imide filled with nanoparticles of silica with the base polymer. No information on the content of the nanoparticles was given, although the authors mentioned that the silica nanoparticles were spherical and had a diameter of 2 to $4 \mathrm{~nm}$. The interesting aspect of this publication is that, although it also indicates the superiority of the nanofilled enamel compared to the base polymer regarding life endurance and discharge resistance, it points out to the fact that relative humidity $(\mathrm{RH})$ plays a vital role affecting the partial discharge behavior, rendering at higher values of RH (at about $80 \% \mathrm{RH}$ ) somehow blurred the distinction between the nanocomposite and the base polymer.

For inverter-operated motors, materials such as ester amide, and amide-imide enamels were introduced, all of them with inorganic nanoparticles to enhance their thermal rating [59], although no precise details were given. In [59], it was emphasized that abrasion resistance and thermal enhancement are critical factors for choosing the right nanocomposite for enameled wires. In [60], besides other topics, the authors mentioned that a polyamide-imide/silica nanocomposite system is suitable for enameled wires since the colloidal state of silica is maintained by covering the silica surface with a new lowhygroscopicity solvent, encouraging thus the dispersion of silica nanoparticles. The latter publication is in agreement with [47]. In [61], the authors tried to modify the surface of silica nanoparticles with two kinds of silanes, with polyesterimide (PEI) as base polymer. They suggested a content of silica nanoparticles of up to $20 \mathrm{wt} \%$, which seems to be far too large. The authors, although the silica-PEI nanocomposite presented a much longer lifetime than the neat PEI in partial discharge conditions, did not give any hints as to the long term stability of such a mixture.

Polyamide-imide resin was mixed with nanoparticles of $\mathrm{Cr}_{2} \mathrm{O}_{3}$ at $14.3 \mathrm{wt} \%$. Conventional samples and samples filled with the aforementioned nanoparticles were investigated w.r.t. their partial discharge behavior. The filled enamel was characterized by lower inception and extinction voltages, which may be due to the enhancement of electric field at wire surfaces owing to the presence of the highly dispersive filler. The exposure to partial discharges was reduced for the filled enamel, but only for the shortest voltage rise time, whereas the effect was not noticed for the longer voltage rise times. This may be due to the decay of charges on the wire surface [62]. The careful reader, however, has to note that the nanoparticle content was far too high. In [63], particular attention was paid to the way a nanocomposite is manufactured. According to the authors of [63], a colloidal state in which particles are dispersed without aggregation by an electrical double layer is preferred and thus a colloid-solution-mixture method was proposed in which the nanocomposite shows a remarkable stability and no viscosity change, even after several months. Lifetime characteristics of enamel with silica nanoparticles were investigated in [64], where it was shown that the mixture with $5 \mathrm{wt} \%$ content had the best V-N characteristics under repetitive surge voltage application, and in descending order the mixtures with $2.5 \mathrm{wt} \%$ and $1 \mathrm{wt} \%$. Moreover, the nanocomposites indicated a better resistance to deterioration than the conventional enamel. The observations and conclusions of [64] were not different from those published in [65].

\section{DISCUSSION AND PERSPECTIVES}

From the above it is evident that enameled wire insulation when mixed with nanoparticles presents a reasonable alternative to conventional enameled insulation. The present paper tries to give a short insight of the complexities of the enameled nanocomposite insulation. The present review is by no means a thorough review of the entire subject of enameled insulation. As discussed above, there is a variety of possibilities regarding the different inorganic nanoparticles. However, no definite conclusions have been reached as yet. There is still an ongoing debate about what are the best nanoparticles, what is the best method of forming a nanocomposite, what is the optimum percentage of the nanoparticles to be included. There is also an ongoing debate about the stability of nanocomposites in general [5], and of enameled nanocomposite insulation in particular [63]. As in other high voltage applications, nanocomposites in the present case depend on the base material, the type of the added nanoparticles, the way of mixing the nanoparticles with the base material and the percentage of the nanoparticles [66]. The response of the enameled nanocomposites depends (among other factors) - as with conventional insulating materials - on the level of applied voltage, temperature, humidity and the type of applied voltage waveform. Since the present review is concentrated on the enameled nanocomposites, the effect of the applied voltage waveform as well as of the other factors will be the subject of another review paper.

A subject which is rather neglected also in enameled nanocomposite insulation is that of the possible charging effects below the so-called inception voltage. Some work, carried out in other insulating materials, indicated that there are charging effects below the inception voltage [67-69]. Since there is a continuing discussion about charge packets in polymeric materials [70], it would be of interest to see whether charging effects below inception have a relation to the charge packets. Furthermore, the lifetime of twisted pairs - having nanocomposite insulation - due to various types of voltages and under different environmental conditions is of immense interest to both the industry and the academy [58, 71]. A closer investigation of enameled nanocomposites may also give a better understanding as to the workings of interfaces [72].

\section{CONCLUSION}

Some crucial aspects have been discussed in the context of this paper. The advent of power electronics arrangements as well as of new materials poses new challenges to the insulation of enameled wires. Well known issues and techniques have to be investigated under the light of the new materials. The advent of new insulating materials, such as nanocomposites, offers new ways of solving insulation challenges. However, new 
materials are not free of defects and/or problems. Questions to be answered have to do, among others, with the lifetime of the new materials, the influence of various types of applied voltages, their way of preparation and the optimum percentage of nanoparticles to be included in a nanocomposite. The longterm stability of any proposed nanaocomposite is also of critical importance. In the coming years, in motor wires insulation as well as in other areas of high voltage engineering, such new materials have to be thoroughly and meticulously further researched.

\section{REFERENCES}

[1] S. V. Kjaer, J. Holboll, "System for detection and analysis of partial dischargesunder transient voltage application", Proceedings of Nordic Insulation Symposium, Trondheim, Norway, pp. 75-78, June 9-12, 2013

[2] B. de Vivo, P. Lamberti, R. Raimo, V. Tucci, L. Guadagno, L. Vertuccio, V. Vittoria, "Evaluation of the electrical properties of epoxybased nanocompositesmotor insulation", Proceedings of the 8th International Symposium onDiagnostics for Electrical Machines, Power Electronics and Drives (SDEMPED 2011), Bologna, Italy, pp. 426-430, September 5-8, 2011

[3] T. J. Lewis, "Nanometric dielectrics", IEEE Transactions on Dielectrics and Electrical Insulation, Vol. 1, No. 5, pp. 812-825, 1994

[4] T. Tanaka, "Dielectric nanocomposites with insulating properties", IEEE Transactions on Dielectrics and Electrical Insulation, Vol. 12, pp. 914928, 2005

[5] J. Keith Nelson (editor), Dielectric Polymer Nanocomposites, Springer, Heidelberg, Germany, 2010

[6] D. Kind, D. Kaerner, High-Voltage Insulation Technology, Vieweg, Braunschweig, Germany, 1985

[7] J. Heighes, "Production and applications of solid insulants", pp. 130146, in Electrical Insulation, edited by A. Bradwell, Peter Peregrinus, London, UK, 1983

[8] http://www.mwswire.com/pdf_files/mws_tech_book/page2_3.pdf

[9] H. Wang, Alterung von Isoliersystemen elektrischer Maschinen imReversierbetrieb, Ph. D. Thesis, Universitaet Gesamthochschule Essen, Fachbereich Maschinenwesen, 1998

[10] E. L. Brancato, L. M. Johnson, F. J. Campbell, H. P. Walker, Reliability Prediction Studies on Electrical Insulation: Navy Summary Report, Naval Research Laboratory, NRL Report 8095, Washington, D. C., USA, 1977

[11] E. L. Brancato, "Estimation of lifetime expectancies of motors", IEEE Electrical Insulation Magazine, Vol. 8, No. 3, pp. 5-13, 1992

[12] E. O. Forster, R. Bartnikas, E. Brancato, F. Campbell, T. Dakin, G. Link, T. Orbeck, C. Reed, E. Sacher, "Research needs to assess the long-term performance of electrical insulating materials and systems", Task Force on Aging of Electrical Insulation, National Academy of Sciences, Washington, D. C., USA, 1977

[13] K. N. Mathes, "Thermal aging of electrical insulation - Technology and standardization", Conference Record of the 1985 International Conference onProperties and Applications of Dielectric Materials, Xi'an, China, pp. 299-302, June 24-29, 1985

[14] W. Weizheng, "A brief review on development and application of insulatingmaterials in China", Conference Record of the 1985 International Conference on Properties and Applications of Dielectric Materials, Xi' an, China, pp. 1-8, June 24-29, 1985

[15] L. J. Payette, "Solderable wire enamel", IEEE Electrical Insulation Magazine,Vol. 6, No. 5, pp. 8-12, 1990

[16] A. J. Battisti, C. Lin, "New developments in solventless polyester varnishes", IEEE Electrical Insulation Magazine, Vol. 7, No. 5, pp. 2126, 1991

[17] M. G. Danikas, R. Sarathi, "Interfaces in high-voltage engineering: A mostimportant question for conventional solid insulating materials as well as for nanocomposite polymers", Funktechnikplus\#Journal, Vol. 1, No. 4, pp. 7-31, 2014
[18] J. K. Nelson, "The promise of dielectric nanocomposites", Conference Record of 2006 IEEE International Symposium on Electrical Insulation, Toronto, Canada, pp. 452-457, June 11-14, 2006

[19] G. Melissinos, M. G. Danikas, "On polymers nanocomposites: Electrical treeing, breakdown models and related simulations", Engineering, Technology \&Applied Science Research, Vol. 8, No. 2, pp. 2627-2632, 2018

[20] G. Melissinos, Breakdown models of polymer nanocomposites, Diploma Thesis, Democritus University of Thrace, Department of Electrical and Computer Engineering, Xanthi, Greece, 2016 (in Greek)

[21] T. Tanaka, "A novel concept for electronic transport in nanoscale spaces formedby islandic multi-cored nanoparticles", Proceedings of 2016 IEEE InternationalConference on Dielectrics (ICD), Montpellier, France, July 3-7, 2016

[22] Y. Nyanteh, L. Graber, C. Edrington, S. Srivastava, D. Cartes, "Overview ofsimulation models for partial discharge and electrical treeing to determine feasibilityfor estimation of remaining life of machine insulation systems", Proceedings of 2011 Electrical Insulation Conference, Annapolis, Maryland, USA, pp. 327-332, June 5-8, 2011

[23] M. G. Danikas, T. Tanaka, "Nanocomposites - A review of electrical treeing and breakdown", IEEE Electrical Insulation Magazine, Vol. 25, No. 4, pp. 19-25, 2009

[24] T. Tanaka, T. Imai, "Advances in nanodielectric materials over the past 50 years", IEEE Electrical Insulation Magazine, Vol. 29, No. 1, pp. 1023, 2013

[25] E. David, M. Frechette, "Polymer nanocomposites - Major conclusions and achievements reached so far", IEEE Electrical Insulation Magazine, Vol. 29, No. 6,pp. 29-36, 2013

[26] E. A. Cherney, "Nanodielectrics applications - Today and tomorrow", IEEE Electrical Insulation Magazine, Vol. 29, No. 6, pp. 59-65, 2013

[27] M. G. Danikas, A. Bairaktari, R. Sarathi, A. Basri Bin Abd Ghani, "A review of twonanocomposite insulating materials models: Lewis' contribution in the developmentof the models, their differences their similarities and future challenges", Engineering, Technology \& Applied Research, Vol. 4, No. 3, pp. 636-643, 2014

[28] M. C. Hawfield, "The origins of the magnet wire industry in America", IEEE Electrical Insulation Magazine, Vol. 15, No. 3, pp. 5-8, 1999

[29] E. Kuffel, W. S. Zaengl, J. Kuffel, High Voltage Engineering: Fundamentals, Newness, Oxford, UK, 2000

[30] T. J. A. Hammarstroem, T. Bengtsson, J. Blennow, S. M. Gubanski, "Partial discharges in motor wires at PWM voltages of different smoothness", Proceedingsof the International Symposium on Electrical Insulating Materials, Niigara City, Japan, June 1-5, 2014

[31] S. Li, S. Yu, Y. Feng, "Progress in and prospects for electrical insulatingmaterials", High Voltage, Vol. 1, No. 3, pp. 122-129, 2016

[32] I. Plesa, P. V. Notingher, S. Schloegl, C. Sumereder, M. Muhr, "Properties of polymer composites used in high-voltage applications", Polymers, Vol. 8, pp. 1-63, 2016

[33] F. Guastavino, C. Gianoglio,. Torello, M. Ferraris, W. Gianelli, "Behaviour of conventional and nanofilled impregnation resins when subjected to PD activity", Proceedings of 2018 2nd IEEE International Conference on Dielectrics (ICD 2018), Budapest, Hungary, pp. 737-739, July $1-5,2018$

[34] R. E. Hebner, "Electrical insulation challenges for rotating machines used onfuture electric ships", Proceedings of 2007 Electrical Insulation Conference andElectrical manufacturing Expo, Nashville, TN, USA, pp. 236-239, October 22-24, 2007

[35] V. Mentlik, J. Pihera, O. Taborik, P. Trnka, "The influence of pulse stress on main-wall insulation of electrical rotating machines", Zeszyty Problemowe, Vol. 77, pp. 43-46, 2007

[36] M. Birle, C. Leu, S. Bauer, "Design and application of a higher frequency high-voltage generator", Proceedings of XVII International Symposium on HighVoltage Engineering, Hannover, Germany, August 22-26, 2011

[37] P. Mraz, V. Kindl, K. Hruska, "Influence of low-conductive coating on insulationsystem of rotary electric machine", Journal of Electrical Engineering, Vol. 63, No. 3, pp. 180-185, 2012 
[38] D. Edison Selvaraj, S. Usa, C. Pugazhendhi Sugumaran, "Comparative analysis ofdielectrtic properties of enamel filled with various nanofillers such as $\mathrm{ZrO} 2, \mathrm{Al} 2 \mathrm{O} 3, \mathrm{CNT}$ and $\mathrm{ZnO}$ ”, International Journal of Science and Engineering Applications, Vol. 1, No. 1, pp. 51-55, 2012

[39] M. Mesaki, Y. Tatematsu, H. Goda, "Hybrid composites of polyamideimide andsilica applied to wire insulation", Furukawa Review, No. 22, pp. $1-4,2002$

[40] http://www.hitachi-cable.com/products/news/20110512.html

[41] X. Ma, S.-J. Kim, "Synthesis and characterization of silica/polyamideimide composite film for enamled wire", available at: http://cdn.intechopen.com/pdfs/30953/InTech-Synthesis_and_characteris ation_of_silica_polyamide_imide_composite_film_for_enamel_wire.pdf

[42] X. Ma, N.-H. Lee, H. -J. Oh, J. -S. Hwang, S. -J. Kim, "Preparation and characterization of silica/polyamide-imide nanocomposite thin films", Nanoscale Research Letters, Vol. 5, pp. 1846-1851, 2010

[43] B. Gornicka, K. Prociov, "Insulating system of inverter-driven motors based on nanocomposites", Materials and Manufacturing Processes, Vol. 24, pp. 1202-1206, 2009

[44] R. Duckworth, T. Aytug, M. Parans Paranthaman, K. Leonard, G. Polyzos, I. Sauers, "Radiation resistant electrical insulation materials for nuclear reactorsusing novel nanocomposite dielectrics", available at: https:/www.energy.gov/sites/prod/files/2013/09/f2/8-NEET_WebinarD uckworth.pdf

[45] L. S. Schadler, J. K. Nelson, C. Calabrese, A. Travelpiece, D. L. Schweickart, "High temperature breakdown strength and voltage endurance characterizationof nanofilled polyamideimide", IEEE Transactions on Dielectrics and ElectricalInsulation, Vol. 19, No. 6, pp. 2090-2101, 2012

[46] C. Pazhanimuthu, "Investigation of dielectric and thermal properties on nanodielectric materials in electrical applications", International Journal of Engineering and Innovative Technology, Vol. 2, No. 2, pp. 62-67, 2012

[47] H. Kikuchi, H. Hanawa, Y. Honda, "Development of polyamideimide/silicananocomposite enameled wire", Electronics and Communications in Japan, Vol. 96, No. 6, pp. 41-48, 2013

[48] D. Muto, M. Oya, T. Aoi, T. Ueno, "A study on partial discharge phenomena of winding wires", Furukawa Review, No. 45, pp. 13-21, 2014

[49] S. Grzybowski, A. Mani, C. D. Taylor, "Partial discharge patterns of magnet wire samples under voltage stresses", 2005 Annual Report of Conference on Electrical Insulation and Dielectric Phenomena, Nashville, USA, pp. 422-425, October 16-19, 2005

[50] K. Inuzuka, H. Inano, N. Hayakawa, T. Hirose, M. Hamaguchi, H. Okubo, "Partial discharge characteristics of nanocomposite enameled wire for inverter-fed motor", 2006 Annual Report of Conference on Electrical Insulation andDielectric Phenomena, Kansas City, USA, pp. 594-597, October 15-18, 2006

[51] C. Mayoux, Contribution a l' etude de l' action, sur du polyethylene, de differentes formes d' energie presents dans les decharges partielles, $\mathrm{PhD}$ Thesis, Universite Paul Sabatier, 1972

[52] W. A. Izzati, Y. Z. Arief, Z. Adzis, M. Shafanizam, "Partial discharge characteristics of polymer nanocomposite materials in electrical insulation: A review of sample preparation techniques, analysis methods, potential applications, and future trends", The Scientific World Journal, Art. No. 735070, pp. 1-14 pages, 2014

[53] A. Krivda, J. Kindersberger, T. Tanaka, A. Vaughan, M. Frechette, S. Pelissou, J. Castellon, Y. Tanaka, D. Fabiani, G. -C. Montanari, L. E. Schmidt, R. Gorur, G. Iyer, P. Morshuis, T. Andritsch, S. Gubanski, J. Seiler, J. Anglhuber, "Characterization of epoxy microcomposite and nanocomposite materials forpower engineering applications", IEEE Electrical Insulation Magazine, Vol. 28, No. 2, pp. 38-51, 2012

[54] B. Gornicka, L. Gorecki, K. Gryzlo, D. Kaczmarek, D. Wojcieszak, "Evaluation of polyesterimide nanocomposites using methods of thermal analysis", IOP Conf. Series: Materials Science and Engineering, Vol. 113, pp. $1-4,2016$

[55] P. Wang, G. -N. Wu, Y. Luo, G.Y. Zhu, "Effect of repetitive square voltagefrequency on partial discharge features", Science China (Technological Sciences), Vol. 56, No. 6, pp. 1313-1321, 2013
[56] S. U. Haq, A study on insulation problems in drive fed medium voltage induction motors, Ph.D. Thesis, University of Waterloo, Waterloo, Canada, 2007

[57] M. Kozako, N. Fuse, Y. Ohki, T. Okamoto, T. Tanaka, "Surface degradation of polyamide nanocomposites caused by partial discharge using IEC (b) electrodes", IEEE Transactions on Dielectrics and Electrical Insulation, Vol. 11,pp. 833-838, 2004

[58] F. Guastavino, A. Ratto, "Comparison between conventional and nanofilledEnamels under different environmental conditions", IEEE Electrical Magazine,Vol. 28, No. 4, pp. 35-41, 2012

[59] C. Reed, "Advances in polymer dielectrics over the past 50 years", IEEE Electrical Insulation Magazine, Vol. 29, No. 4, pp. 45-51, 2013

[60] T. Tanaka, T. Imai, "Advances in nanodielectric materials over the past 50 Years”, IEEE Electrical Insulation Magazine, Vol. 29, No. 1, pp. 1023, 2013

[61] J. Yoo, Y. Kim, S. Kwon, J. Lee, Y. -S. Seo, "Surge-resistant nanocomposite enameled wire using silica nanoparticles with binary chemical compositions onthe surface", Journal of Nanomaterials, Art. No. 231672, pp. 1-8, 2015

[62] A. T. Hoang, Electrical characterization of partial discharge resistant enamel insulation, Thesis for the Degree of Licentiate of Engineering, Chalmers University of Technology, Department of Materials and Manufacturing Technology, High Voltage Engineering, Goeteborg, Sweden, 2014

[63] H. Kikuchi, H. Hanawa, "Inverter surge resistant enameled wire with nanocomposite insulating material", IEEE Transactions on Dielectrics and Electrical Insulation, Vol. 19, No. 1, pp. 99-106, 2012

[64] N. Hayakawa, H. Okubo, "Lifetime characteristics of nanocomposite enameled wire under surge voltage application", IEEE Electrical Insulation Magazine, Vol. 24, No. 2, pp. 22-27, 2008

[65] Y. Nakamura, H. Inano, N. Hayakawa, S. Hiroshima, T. Hirose, M. Hamaguchi, H. Okubo, "Lifetime characteristics of nanocomposite enameled wire under surge voltage application", Proceedings of International Symposium on EcoTopia Science 2007 ISETS07, pp. 496497, Japan, 2007

[66] T. Andritsch, D. Fabiani, I. Ramirez Vazquez, "Nanodielectrics Examples of preparation and microstructure", IEEE Electrical Insulation Magazine, Vol. 29, No. 6, pp. 21-28, 2013

[67] A. M. Bruning, D. G. Kasture, F. G. Campbell, N. H. Turner, "Effect of cavity sub-corona current on polymer insulation life", IEEE Transactions on Electrical Insulation, Vol. 26, No. 4, pp. 826-836, 1991

[68] M. G. Danikas, X. Zhao, Y. -H. Cheng, "Experimental data on epoxy resin samples: Small partialdischarges at inception voltage and some thoughts on the possibility of the existence of charging phenomena below inception voltage", Journal of Electrical Engineering, Vol. 62, No. 5, pp. 292-296, 2011

[69] Y. Zhang, M. G. Danikas, X. Zhao, Y. Cheng, "Preliminary experimental work on nanocomposite polymers: Small partial discharges at inception voltage, the existence of possible charging mechanisms below inception voltage and the problem of definitions", Journal of Electrical Engineering, Vol. 63, no. 2, pp.109-114, 2012

[70] D. Fabiani, G. -C. Montanari, L. A. Dissado, C. Laurent, G. Teyssedre, "Fast and slow charge packets in polymeric materials under DC stress", IEEE Transactions on Dielectrics and Electrical Insulation, Vol. 16, No. 1, pp.241-250, 2009

[71] N. S. Rao, K. Elanseralathan, "Influence of square waveform on life of twisted pairs due to power electronic converters", The Journal of CPRI, Vol. 13, No. 1, pp. 135-140, 2017

[72] D. Pitsa, M. G. Danikas, "Interfaces features in polymer nanocomposites: A review of proposed models", NANO: Brief Reports and Reviews, Nol. 6, No. 6, pp. 497-508, 2011 